\title{
Characterization of donepezil prepared by cogrinding with salicylic acid and $p$-aminobenzoic acid
}

\author{
Weenawan Somphon*, Sirimol Makatan \\ Department of Chemistry, Faculty of Liberal Arts and Science, Kasetsart University, \\ Kamphaeng Saen Campus, Nakhon Pathom 73140 Thailand \\ *Corresponding author, e-mail: faaswnw@ku.ac.th
}

Received 18 Jan 2018

Accepted 16 Feb 2019

\begin{abstract}
Two systems for the formation of cocrystals of donepezil were investigated using donepezil hydrochloride and donepezil solvate with salicylic acid and $p$-aminobenzoic acid. The donepezil solvate was prepared through an acidbase reaction between a hydrochloride salt and a base in methanol. Donepezil $\mathrm{HCl}(\mathrm{DH})$ and the solvate with salicylic acid and $p$-aminobenzoic acid (PABA) at 1:1 molar ratios were prepared using the cogrinding method. Cocrystals were characterized using attenuated total reflection-FTIR spectroscopy (ATR-FTIR), nuclear magnetic resonance spectroscopy $\left({ }^{13} \mathrm{C}\right.$ and ${ }^{1} \mathrm{H}$ NMR), Powder X-ray diffraction, and differential scanning calorimetry. These results indicate that the cogrinding process could induce cocrystal formation in donepezil systems through a simple process that allows for rapid screening of cocrystals of donepezil.
\end{abstract}

KEYWORDS: donepezil hydrochloride, donepezil solvate, pharmaceutical solids, screening, spectroscopy

\section{INTRODUCTION}

The efficiency of an oral drug is dependent on its physical and chemical properties. One of the challenges in the drug development processes is to improve the performance and physicochemical properties of oral delivery of solid state drugs ${ }^{1-3}$. Drugs or other active pharmaceutical ingredients (APIs) typically exist in several solid forms such as polymorphs, hydrates, solvates, salts, cocrystals, and amorphous solids ${ }^{4,5}$. Cocrystal formation is one technique used in the development of new oral solid state forms of APIs ${ }^{6,7}$. Pharmaceutical cocrystals are a subclass of cocrystals that have been defined by the US Food and Drug Administration (FDA), as APIs (neutral or ionized) and excipients (or coformers) present at a stoichiometric ratio in a single crystal lattice. Mixtures of APIs and coformers can form cocrystals (neutral molecules), salts (proton transfer charged molecules), and cocrystal salts (charged and neutral molecules in a compound). Cocrystals of APIs have been optimized to have greatly improved physicochemical properties, such as solubility, stability, bioavailability, and hygroscopicity. Cocrystallization can generate new crystal structures and may produce forms that provide properties beneficial for an oral dosage drug $^{8-11}$. To date, most of the literature on cocrystals of APIs has focused on poorly soluble market drugs ${ }^{12-14}$. Industrial processing has primarily concentrated on producing neutral drugs that contain an amine, examples are fexofenadine and paroxetin. These drugs have typically been crystallized with $\mathrm{HCl}$ to increase their solubility in water $^{15,16}$. However, undesirable side effects in the stomach can occur with these preparations. We are interested in the development of a method to form cocrystals of an ionized API. Previous studies have shown that there are opportunities for improving the physical properties of solid forms of drugs such as fluoxetine $\mathrm{HCl}$ (Prozac) ${ }^{17}$, Ivabradine $\mathrm{HCl}^{18}$, and tramadol $\mathrm{HCl}^{19}$. Cocrystallization of drug salts has a number of advantages including providing improved stability, solubility, and dissolution rate.

Donepezil $\mathrm{HCl}(\mathrm{DH})$ is used to treat Alzheimer's disease $(\mathrm{AD})$ and is a reversible acetylcholinesterase inhibitor $^{20}$. Donepezil has improved the cognitive function of patients with mild-to-moderate $\mathrm{AD}$ diseases. This drug is considered safe and patients have shown a high tolerance to extended treatment ${ }^{21,22}$. However, the high absorption and high lipophilicity of DH may cause side effects in the gastrointestinal system $^{23}$. Furthermore, the DH crystal structure is unstable and can be transformed into several anhydrous and hydrates forms ${ }^{24-27}$. These crystal transformations can result in polymorphs with different chemical and physical properties, compared to the original $\mathrm{DH}$ crystals, resulting in altered bioavailability. In addition, $\mathrm{DH}$ has an extremely 


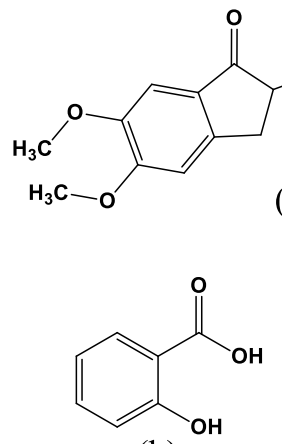

(b) (a)
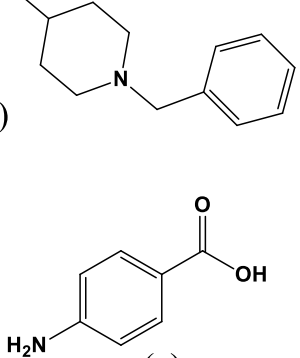

(c)
Fig. 1 Chemical structures of (a) donepezil, (b) salicylic acid, and (c) p-aminobenzoic acid.

bitter taste when taken orally; thus, improved physicochemical properties of DH may aid in patient compliance. Salt formation from donepezil with oxalic $\operatorname{acid}^{28}$, with various carboxylic acids (e.g., maleic acid, fumaric acid, citric acid, salicylic acid, tartaric acid, and succinic acid) ${ }^{29}$, salicylic acid and derivatives ${ }^{30}$, and sulfonic acids ${ }^{31}$ have been reported. Patients claimed that the new donepezil salts, which were mixed with carboxylic acids (including salicylic acid), prevented the bitter taste of $\mathrm{DH}^{29}$.

In this study, we were interested in donepezilsalicylate and donepezil hydrochloride-salicylic acid, which occur in several polymorphic forms and that exhibit strong fluorescence in a salt solvate, e.g., 3-, and 5-methylsalicylate methanolate ${ }^{30}$. However, these salts or cocrystals have been created using traditional solution-based methods. The grinding method, a technique is routinely used in the pharmaceutical industry, is proposed as an alternative for forming donepezil cocrystals. We attempted to form cocrystals of donepezil $\mathrm{HCl}$ and the solvate using a cogrinding method as two coformers (salicylic acid and $p$-aminobenzoic acid). Both coformers are involved as primary compounds in the synthesis of pharmaceutical compounds ${ }^{32-34}$. The approach taken aimed to understand the mechanisms involved in the process-induced cocrystal formation and to develop a solvent-free method.

\section{MATERIALS AND METHODS}

\section{Chemicals and solvents}

Donepezil hydrochloride (DH), salicylic acid (SA), and $\mathrm{NaOH}$ were purchased from Sigma-Aldrich, and $p$-aminobenzoic acid (PABA) from Acros Organics. All chemicals ( $>98 \%$ purity) were used without any further purification. All solvents used were analytical grade. The chemical structures of donepezil and the two coformers are shown in Fig. 1.

\section{Preparation of donepezil solvate}

Donepezil solvate (DP-M) was prepared the same as previously described ${ }^{35}$ with slight modification. To a solution of DH $(0.02 \mathrm{mmol}, 8.3 \mathrm{mg})$ in methanol $(2 \mathrm{ml}) 1.0 \mathrm{M} \mathrm{NaOH}(4.0 \mathrm{ml})$ was added. Colourless fine crystals were obtained and analysed using ATRFTIR, PXRD, and DSC.

\section{Preparation of donepezil} hydrochloride/donepezil solvate with coformers

Cogrinding in 1:1 $\mathrm{M}$ ratios of DH and DP-M with coformers (SA and PABA) was performed in all combinations. Preparations contained $0.02 \mathrm{mmol}$ of DH (8.3 mg), DP-M (8.2 mg), and coformers: SA (0.02 mmol, $2.8 \mathrm{mg}$ ); PABA (0.02 mmol, $2.7 \mathrm{mg}$ ) which were ground for approximately $30 \mathrm{~min}$ using a mortar and pestle.

\section{Attenuated total reflection-FTIR spectroscopy (ATR-FTIR)}

IR spectra were collected on a Perkin-Elmer model Spectrum GX spectrometer, over the range of 4000$500 \mathrm{~cm}^{-1}$ with a UATR and a diamond/ZnSe crystal accessory.

\section{Nuclear magnetic resonance $\left({ }^{13} \mathrm{C}\right.$ and ${ }^{1} \mathrm{H}$ NMR) spectroscopy}

Experiments were performed on a Bruker Avance $300(300 \mathrm{MHz})$ spectrometer in $\mathrm{CD}_{3} \mathrm{Cl}$ at room temperature.

\section{Powder X-ray diffraction (PXRD)}

PXRD spectra were recorded on a Bruker AXS D8 Advance diffractometer, equipped with a $\mathrm{Cu} K_{\alpha}$ sealed tube X-ray source operating at $40 \mathrm{kV}$ and $30 \mathrm{~mA}$. The data were collected in the range $3-90^{\circ}$ $2 \theta$ in steps of $0.02^{\circ}$ with a scanspeed of $0.5 \mathrm{~s} / \mathrm{step}$.

\section{Differential scanning calorimetry (DSC)}

DSC was performed on an NETZSCH DSC 204 F1 Phoenix differential scanning calorimeter. Samples were placed in aluminium pans under nitro- 
gen (flow rate $30 \mathrm{ml} / \mathrm{min}$ ) with a heating rate of $5^{\circ} \mathrm{C} / \mathrm{min}$ in the range $25-380^{\circ} \mathrm{C}$.

\section{RESULTS AND DISCUSSION}

\section{Characterization of donepezil solvate}

FTIR absorbance spectra of the donepezil solvate (DP-M) was compared with DH (Fig. 2). The spectra of the DP-M does not exhibit bands $v(\mathrm{~N}-\mathrm{H})$, $\mathrm{NH}^{+}$at $2460,2420,2406$, and $2389 \mathrm{~cm}^{-1}$ in DH. The $v(\mathrm{C}=\mathrm{O})$ of $\mathrm{DH}$ at $1698 \mathrm{~cm}^{-1}$ was shifted to $1682 \mathrm{~cm}^{-1}$. The $v(\mathrm{C}-\mathrm{N})$ of $\mathrm{DH}$ at $1312 \mathrm{~cm}^{-1}$ was shifted to $1306 \mathrm{~cm}^{-1}$ for DP-M. Furthermore, DP-M had a band of $v(\mathrm{O}-\mathrm{H})$ at $3364 \mathrm{~cm}^{-1}$ that belonged to the $\mathrm{OH}$ group from the methanol in the lattice (Fig. 2a). The DSC thermograms and PXRD patterns of DP-M are shown in Fig. 2bc. There were endothermic peaks at 87.5 and $94.8^{\circ} \mathrm{C}$, which corresponded to the evaporation of $\mathrm{MeOH}$ and melting point of donepezil. Diffraction peaks of DP$\mathrm{M}$ were detected at $2 \theta=5.6,11.3,22.9,23.4$, $34.2^{\circ}$. This clearly confirmed the presence of a new solid form, which is closely resembled structures in literature $\mathrm{e}^{30,36}$.

\section{Donepezil $\mathrm{HCl}$ and the donepezil solvate cogrinding systems}

The ATR-FTIR spectra of the cogrinding products are shown in Fig. 3. The DH-SA product had peaks, $v(\mathrm{C}=\mathrm{O})$ at 1696 and $1654 \mathrm{~cm}^{-1}$, compared with DH $\left(1696 \mathrm{~cm}^{-1}\right)$ and SA $\left(1660 \mathrm{~cm}^{-1}\right)$. The $\beta(\mathrm{O}-\mathrm{H})_{\mathrm{c}}$ at $1464 \mathrm{~cm}^{-1}$ of SA was shifted to $1459 \mathrm{~cm}^{-1}$ with almost the complete disappearance in SA of $v(\mathrm{C}-\mathrm{O})_{\mathrm{c}}$ at $1324 \mathrm{~cm}^{-1}$ and $\beta(\mathrm{O}-\mathrm{H})_{\mathrm{h}}$ at $1382 \mathrm{~cm}^{-1}$ shifted to $1385 \mathrm{~cm}^{-1}$. Furthermore, the peak intensity of DH $v(\mathrm{C}-\mathrm{N})$ at $1312 \mathrm{~cm}^{-1}$ decreased and shifted to a weak band at $1309 \mathrm{~cm}^{-1}$ (Fig. 3a). The changes and shifts in the peaks of $v(\mathrm{C}=\mathrm{O})$ and $v(\mathrm{C}-\mathrm{N})$ of $\mathrm{DH}$ in the formation of DH-PABA were similar to those seen with DH-SA formation (Fig. 3b). In DH-PABA, the $v(\mathrm{C}=\mathrm{O})$ at $1660 \mathrm{~cm}^{-1}$ was shifted to $1663 \mathrm{~cm}^{-1}$, the peak intensity of $\beta(\mathrm{O}-\mathrm{H})$ at $1420 \mathrm{~cm}^{-1}$ decreased and the $v(\mathrm{C}-\mathrm{OH})$ band at $1285 \mathrm{~cm}^{-1}$ shifted to $1288 \mathrm{~cm}^{-1}$ (Fig. 3b). The $v(\mathrm{C}=\mathrm{O})$ observed in cocrystals were obtained above $1600 \mathrm{~cm}^{-1}$ and the sharp peak of $v_{s}\left(\mathrm{COO}^{-}\right)$around $1400 \mathrm{~cm}^{-1}$ was not found ${ }^{37,38}$. These results imply that DH may associate with SA and PABA through hydrogen bond interactions of the amine hydrochloride salt, as seen in the spectra of $\mathrm{N}-\mathrm{H}^{+}$present in $\mathrm{DH}$ and with the carboxylic acid of the coformers $\left(2460-2389 \mathrm{~cm}^{-1}\right)$. Furthermore, the chloride ion appears to be acting
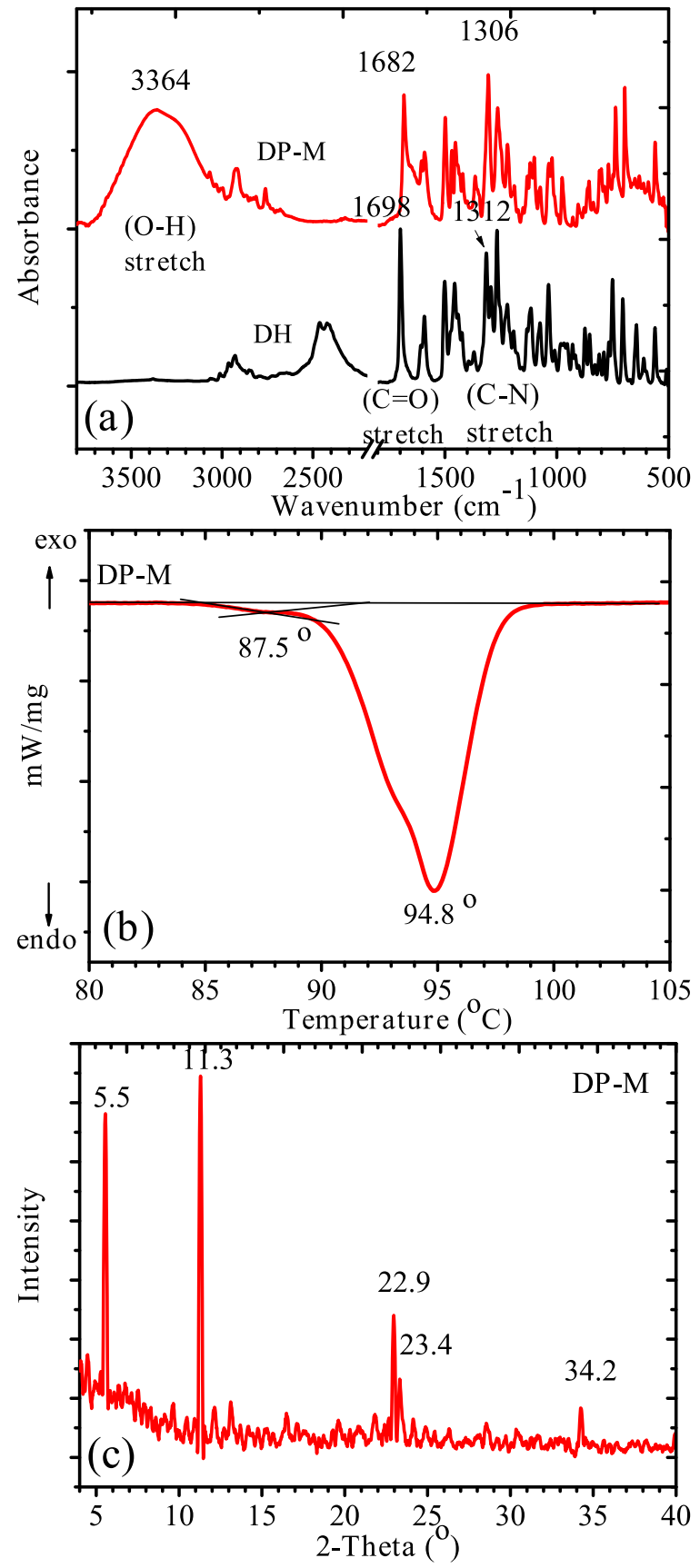

Fig. 2 (a) ATR-FTIR absorption spectra of donepezil hydrochloride (DH) and donepezil solvate (DP-M); (b, c) DSC thermograms and PXRD diffractograms of donepezil solvate.

as a hydrogen donor ${ }^{17}$. These compounds are a cocrystal salt, which contains a positive charge from the piperidyl moiety $\left(\mathrm{N}-\mathrm{H}^{+}\right)$, a negative charge $\left(\mathrm{Cl}^{-}\right)$and a neutral molecule from the coformers. The FTIR absorption spectra of neutral donepezil 

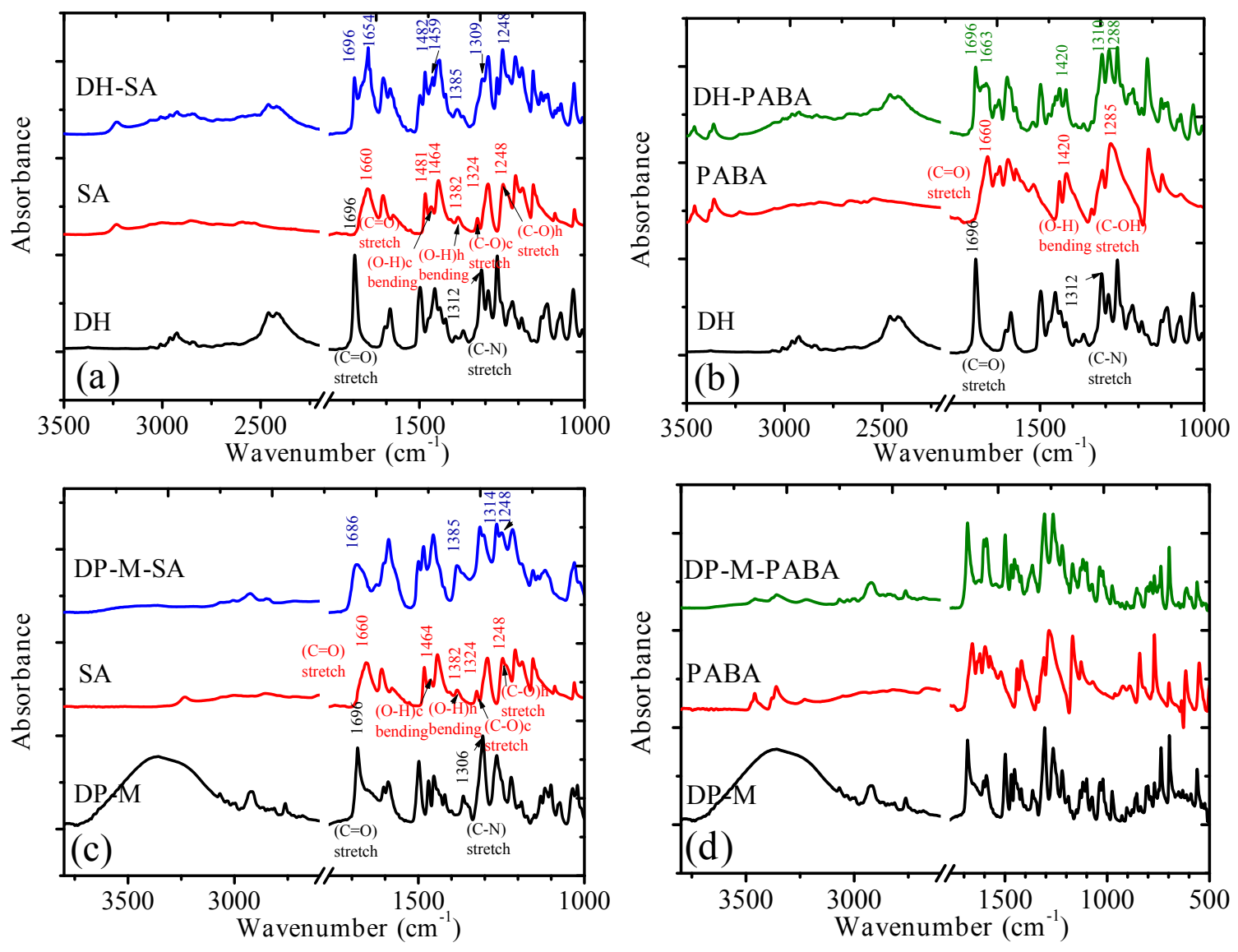

Fig. 3 ATR-FTIR absorption spectra of (a) DH, SA and DH-SA cogrinding products, (b) DH, PABA, and DH-PABA cogrinding products, (c) DP-M, SA and DP-M-SA cogrinding products, and (d) DP-M, PABA and DP-M-PABA cogrinding products.

solvate (DP-M) and with SA and PABA are shown in Fig. 3cd. The DP-M-SA product shows a shift of $v(\mathrm{C}=\mathrm{O})$ at 1660 to $1686 \mathrm{~cm}^{-1}$ in SA. The $\beta(\mathrm{O}-\mathrm{H})_{\mathrm{c}}$ peak in SA-based compounds at $1464 \mathrm{~cm}^{-1}$ was absent, whereas the shifts of $v(\mathrm{C}-\mathrm{N})$ from 1306 to $1314 \mathrm{~cm}^{-1}$ are consistent with DH-SA. The hydroxyl group of SA, $\beta(\mathrm{O}-\mathrm{H})_{\mathrm{h}}$ at $1382 \mathrm{~cm}^{-1}$ and $\nu(\mathrm{C}-\mathrm{O})_{\mathrm{h}}$ at $1248 \mathrm{~cm}^{-1}$, shifted to a medium peak at $1385 \mathrm{~cm}^{-1}$ and a weak peak of $1248 \mathrm{~cm}^{-1}$, respectively. However, the changes of PABA in DP-M-PABA was only slightly shifted compares to the starting materials.

Fig. 4 shows the ${ }^{13} \mathrm{C}$ and ${ }^{1} \mathrm{H}$ NMR spectra of $\mathrm{DH}$, SA, DH-SA, DH-PABA, and DP-M-PABA cogrinding products, respectively. ${ }^{13} \mathrm{C}$ and ${ }^{1} \mathrm{H}$ NMR chemical shifts of donepezil were referenced from earlier studies ${ }^{39}$. The ${ }^{13} \mathrm{C}$ shifts of the piperidine ring- $\mathrm{CH}_{2}$ (C16), the resonance shifted from $60.82 \mathrm{ppm}$ (pure $\mathrm{DH})$ to $60.93 \mathrm{ppm}$ (DH-SA and DH-PABA), and the C15 (piperidine ring) shifted from $52.18 \mathrm{ppm}$ (pure $\mathrm{DH})$ to $52.39 \mathrm{ppm}$ (DH-SA) and $52.30 \mathrm{ppm}$ (DH-
PABA). ${ }^{1} \mathrm{H}$ NMR of DH-SA shows a change the signal of $\mathrm{OH}(\mathrm{OH} 2)$ of SA from $10.39 \mathrm{ppm}$ (pure SA) to $10.71 \mathrm{ppm}$, and C16 (pure DH) signal shift from 4.14 to $4.18 \mathrm{ppm}$. The peaks that are shifted in DH-PABA and DP-M-PABA spectra were distinct. In the case of DH-PABA, the product causes a major interference with the signals, and we could not differentiate the $\mathrm{OH}$ from $\mathrm{COOH}$ signal $(12 \mathrm{ppm}$, $\mathrm{s}$, $1 \mathrm{H})$ and $\mathrm{NH}_{2}(5.9 \mathrm{ppm}, \mathrm{d}, 2 \mathrm{H})$ of PABA ${ }^{40}$. However, a small change of the spectral signal of C16 (4.43$4.48 \mathrm{ppm})$ and C20 (7.64-7.61 ppm) from DH was obtained. The signal of DP-M-PABA shifts signal of C2 (DH) from 3.24-3.33 ppm (m) to 3.07-3.11 ppm (d), C3 (DH) from 3.41-3.52 ppm to 3.18-3.27 ppm (m), C4 (DH) 7.11 to $7.16 \mathrm{ppm}, \mathrm{C} 19$ (DH) from 7.15-7.46 ppm to 7.28-7.37 ppm (t). The C20 (DH) was missing and obtained the signal of $\mathrm{MeOH}$ at $3.54 \mathrm{ppm}$. These signal shifts suggest that the grinding process-induced cocrystal formation.

PXRD thermograms of the components $\mathrm{DH}-$ 

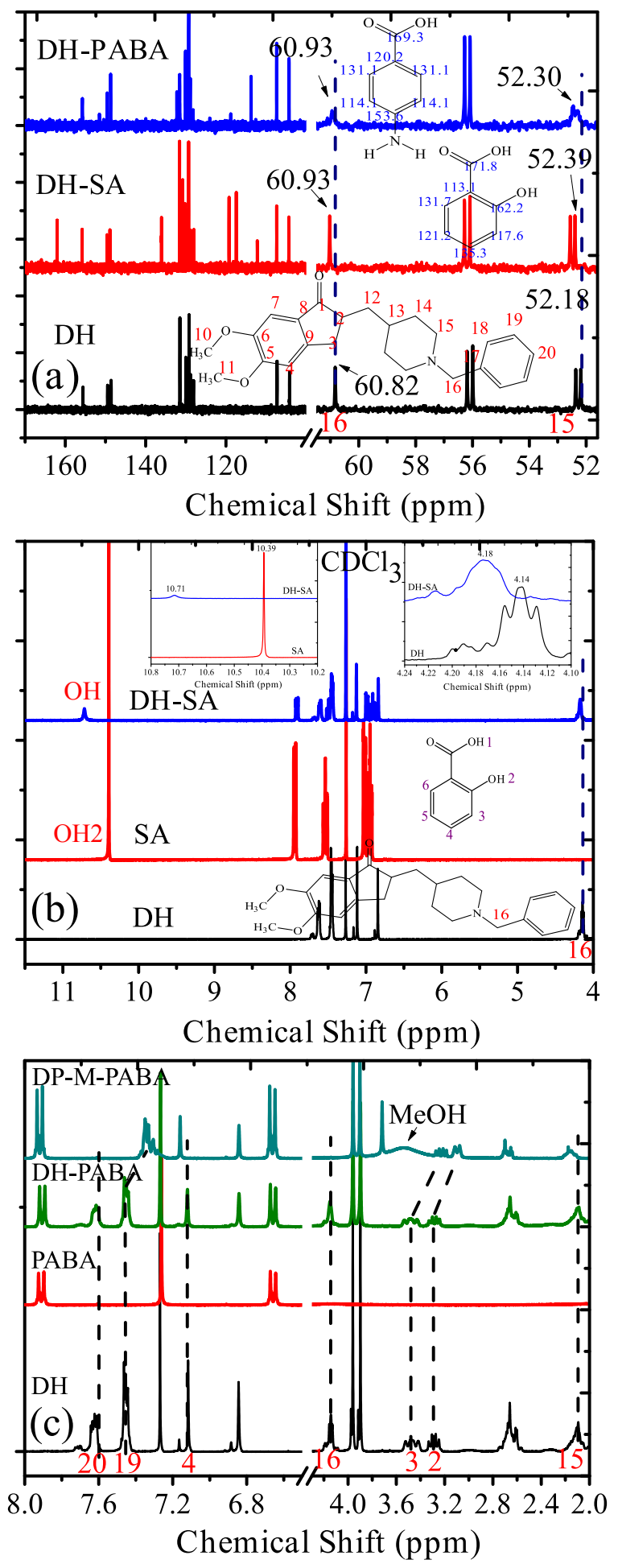

Fig. 4 (a) ${ }^{13} \mathrm{C}$ NMR spectra of DH, DH-SA, and DH-PABA; (b) ${ }^{1} \mathrm{H}$ NMR spectra of DH, SA, and DH-SA; (c) ${ }^{1} \mathrm{H}$ NMR spectra of DH, PABA, DH-PABA, and DP-M-PABA.
SA/DH-PABA and DP-M-SA/DP-M-PABA are shown in Fig. 5. The DH diffraction patterns and $2 \theta$ peaks from I in Ref. 24 were used as a reference. PXRD of DH-SA and DH-PABA show a combination of peaks from the starting materials and new peaks with several weak intensities due to unreacted components (Fig. 5a). Amorphous phases for the DP-M-SA and crystalline phases DP-M-PABA are shown in Fig. 5b. However, the diffraction patterns of all products were distinguishable from those of the starting materials. These results indicate the formation of a new crystal phase. DSC measurements of pure APIs (DH and DP-M), coformers (SA and PABA) and the physical mixtures from the cogrinding samples were obtained. Fig. 6ab show the DSC curves of the DHSA and DH-PABA cocrystals. The melting points of $\mathrm{DH}, \mathrm{SA}$, and PABA are $230.5,160.9$, and $191.8^{\circ} \mathrm{C}$, respectively. Endothermic peaks for DH-SA were observed at $100.4,180.4$, and $253.5^{\circ} \mathrm{C}$, and $\mathrm{DH}-$ PABA were observed at $164.8^{\circ} \mathrm{C}$. The DP-M-SA had endothermic peaks at 89.7 (weak), 157 (weak), and $246.8{ }^{\circ} \mathrm{C}$, respectively (Fig. 6c). DP-M-PABA exhibited endothermic peaks at $220^{\circ} \mathrm{C}$ (Fig. 6d). The first and second endothermic temperatures of DH-SA and DP-M-SA represent the melting points of $\mathrm{DH}$ and SA in the different formations. The broad endothermic peaks at 253.5 and $246.8^{\circ} \mathrm{C}$ may correspond to the fusion of the cogrinding powders and include the decomposition temperature of donepezil (DH $\left.225-226^{\circ} \mathrm{C}\right)^{25}$. The endothermic temperature at $164.8^{\circ} \mathrm{C}$ of DH-PABA and at $220^{\circ} \mathrm{C}$ of DP-M-PABA, correspond to the melting point of the cogrinding powders in the different formations. The cogrinding products of the APIs with the coformers resulted in new thermal events with little relationship to the melting peaks of the starting components to indicate the generation of the cocrystal forms.

\section{CONCLUSIONS}

Donepezil solvate was obtained through an acidbase reaction between a hydrochloride salt and a base in methanol. Two systems of donepezil hydrochloride and donepezil solvate (DP-M) with two coformers (salicylic acid and $p$-aminobenzoic acid (PABA) were prepared based on a cogrinding method. FTIR, ${ }^{13} \mathrm{C}$ and ${ }^{1} \mathrm{H}$ NMR, PXRD, and DSC analysis confirmed the process-induced cocrystal salt and cocrystal formations from a solventfree method. Furthermore, this appears to be the first report of the formations of donepezil with $p$ aminobenzoic acid. These findings provide a great opportunity for cocrystal systems where donepezil cocrystals are used in the cogrinding method for 

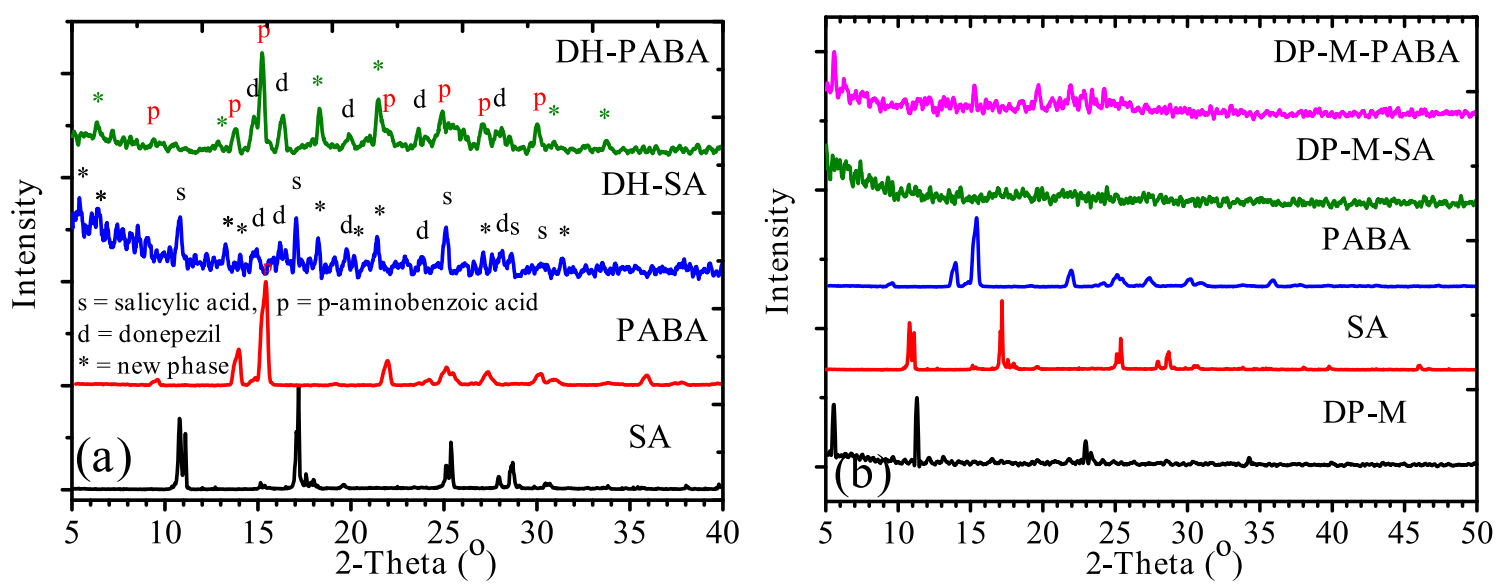

Fig. 5 PXRD patterns of (a) SA, PABA, DH-SA and DH-PABA and (b) DP-M, SA, PABA, DP-M-SA and DP-M-PABA.
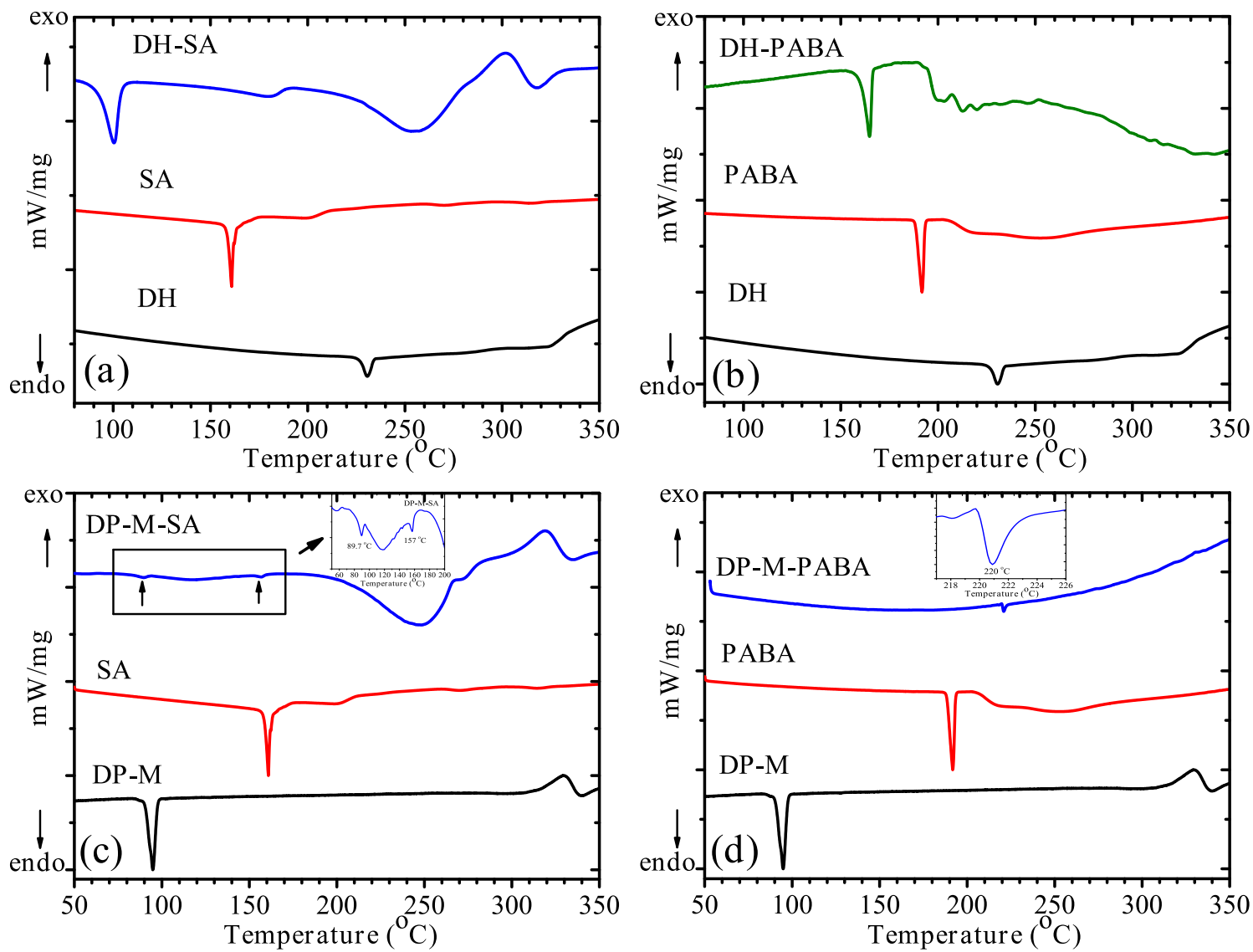

Fig. 6 DSC thermograms of (a) DH, SA and DH-SA, (b) DH, PABA and DH-PABA, (c) DP-M, SA and DP-M-SA, and (d) DP-M, PABA and DP-M-PABA.

preparation. This is an example of new greenchemistry, using a simple process that appears to be well suited for rapid screening of cocrystals of donepezil for industrial processes.
Acknowledgements: We gratefully acknowledge the financial support of Kasetsart University, Thailand for grant No. 582K160140018 in the Chemistry Department and Faculty of Liberal Arts and Science, year 2016 funding. 


\section{REFERENCES}

1. Huang L-F, Tong W-Q (2004) Impact of solid state properties on developability assessment of drug candidates. Adv Drug Deliv Rev 56, 321-34.

2. Khadka P, Ro J, Kim H, Kim I, Kim JT, Kim H, Cho JM, Yun G, et al (2014) Pharmaceutical particle technologies: An approach to improve drug solubility, dissolution and bioavailability. Asian J Pharm Sci 9, 304-16.

3. Qiu Y, Chen Y, Zhang GGZ, Yu L, Mantri RV (2017) Developing Solid Oral Dosage Forms, Pharmaceutical Theory \& Practice, 2nd edn, Elsevier Academic Press.

4. Aitipamula S, Banerjee R, Bansal AK, Biradha K, Cheney ML, Choudhury AR, Desiraju GR, Dikundwar AG, et al (2012) Polymorphs, salts, and cocrystals: what's in a name? Cryst Growth Des 12, 2147-52.

5. Healy AM, Worku ZA, Kumar D, Madi AM (2017) Pharmaceutical solvates, hydrates and amorphous forms: A special emphasis on cocrystals. Adv Drug Deliv Rev 117, 25-46.

6. Almarsson Ö, Zaworotko MJ (2004) Crystal engineering of the composition of pharmaceutical phases. Do pharmaceutical co-crystals represent a new path to improved medicines?. Chem Commun 17, 1889-96.

7. Steed JW (2013) The role of co-crystals in pharmaceutical design. Trends Pharmacol Sci 34, 185-93.

8. Schultheiss N, Newman A (2009) Pharmaceutical cocrystals and their physicochemical properties. Cryst Growth Des 9, 2950-67.

9. Qiao N, Li M, Schlindwein W, Malek N, Davies A, Trappitt G (2011) Pharmaceutical cocrystals: an overview. Int $J$ Pharm 419, 1-11.

10. Vioglio PC, Chierotti MR, Gobetto R (2017) Pharmaceutical aspects of salt and cocrystal forms of APIs and characterization challenges. Adv Drug Deliv Rev 117, 86-110.

11. Shaikh R, Singh R, Walker GM, Croker, DM (2018) Pharmaceutical cocrystal drug products: an outlook on product development. Trends Pharmacol Sci 39, 1033-48.

12. Thakuria R, Delori A, Jones W, Lipert MP, Roy L, Rodríguez-Hornedo N (2013) Pharmaceutical cocrystals and poorly soluble drugs. Int J Pharm 453, 101-25.

13. Karashima M, Kimoto, K, Yamamoto, K, Kojima, T, Iked Y (2016) A novel solubilization technique for poorly soluble drugs through the integration of nanocrystal and cocrystal technologies. Eur J Pharm Biopharm 107, 142-50.

14. Sokal A, Pindelska E, Szeleszczuk L, Kolodziejski W (2017) Pharmaceutical properties of two ethenzamide-gentisic acid cocrystal polymorphs: drug release profiles, spectroscopic studies and theoretical calculations. Int J Pharm 522, 80-9.

15. Yehia SA, El-Ridi MS, Tadros MI, El-Sherif NG (2015)
Enhancement of the oral bioavailability of fexofenadine hydrochloride via cremophor El-based liquisolid tablets. Adv Pharm Bull 5, 569-81.

16. Germann D, Ma G, Han F, Tikhomirova A (2013) Paroxetine hydrochloride. In: Brittain HG (ed) Profiles of Drug Substances, Excipients and Related Methodology, 1st edn, Academic Press, USA, pp 367-406.

17. Childs SL, Chyall LJ, Dunlap JT, Smolenskaya VN, Stahly BC, Stahly GP (2004) Crystal engineering approach to forming cocrystals of amine hydrochlorides with organic acids. Molecular complexes of fluoxetine hydrochloride with benzoic, succinic, and fumaric acids. $J$ Am Chem Soc 126, 13335-42.

18. Sládková V, Dammer O, Sedmak G, Skořepová E, Kratochvíl B (2017) Ivabradine hydrochloride (S)mandelic acid co-crystal: In situ preparation during formulation. Crystals 7, 1-16.

19. Almansa $C$, Mercè $R$, Tesson $N$, Farran J, Tomàs J, Plata-Salamán CR (2017) Co-crystal of tramadol hydrochloride-celecoxib (ctc): a novel API-API cocrystal for the treatment of pain. Cryst Growth Des 17, 1884-92.

20. Sugimoto H, Ogura H, Arai Y, Iimura Y, Yamanishi Y (2002) Research and development of donepezil hydrochloride, a new type of acetylcholinesterase inhibitor. Jpn J Pharmacol 89, 7-20.

21. Jackson S, Ham RJ, Wilkinson D (2004) The safety and tolerability of donepezil in patients with Alzheimer's disease. Br J Clin Pharmacol 58, 1-8.

22. Knowles J (2006) Clinical impact review donepezil in Alzheimer's disease: an evidence-based review of its impact on clinical and economic outcomes. Core Evid 1, 195-219.

23. Tsuno N (2009) Donepezil in the treatment of patients with Alzheimer's disease. Expert Rev Neurother 9, 591-8.

24. Imai $\mathrm{A}$, Watanabe $\mathrm{H}$, Kajima $\mathrm{T}$, Ishihama $\mathrm{Y}$, Ohtsuka A, Tanaka T, Narabu Y (1999) Polymorphs of Donepezil Hydrochloride and Process for Production, US patent, US005985864A.

25. Parthasaradhi BR, Rathnakar RK, Raji RR, Muralidhara RD, Chander RKS (2005) Novel Crystalline Forms of Donepezil Hydrochloride, US patent, US20050215591A1.

26. Park TJ, Ko DH, Kim YJ, Kim Y (2009) Polymorphic characterization of pharmaceutical solids, donepezil hydrochloride, by 13C CP/MAS solid-state nuclear magnetic resonance spectroscopy. Bull Korean Chem Soc 30, 2007-10.

27. Liu T, Wang B, Dong W, Gong J (2013) Solutionmediated phase transformation of a hydrate to its anhydrous form of donepezil hydrochloride. Chem Eng Technol 36, 1327-34.

28. Ravikumar K, Sridhar B, Sathe DG, Naidu AV, Sawant KD (2006) Donepezilium oxalate trihydrate, a therapeutic agent for Alzheimer's disease. Acta Cryst C 62, 
o681-3.

29. Zhang H (2013) Polymorphs of Donepezil Salts, Preparation Methods and Uses Thereof, US patent, US8501779B2.

30. Brittain HG (2014) Spectroscopic studies of solidstate forms of donepezil free base and salt forms with various salicylic acids. $J$ Mol Struct 1078, 207-12.

31. Lee SH, Bae JH, Park Y, Adhikari BR, Mao C, Kim D, Kim KI, Kang SW, et al (2015) Sulfonic acid salts of donepezil and stabilization of amorphous donepezil via formation of amorphous salts. Cryst Growth Des 15, 3123-30.

32. Li Z, Matzger AJ (2016) Influence of coformer stoichiometric ratio on pharmaceutical cocrystal dissolution: three cocrystals of carbamazepine/4aminobenzoic acid. Mol Pharmaceutics 13, 990-5.

33. Sathisaran I, Dalvi SV (2017) Crystal engineering of curcumin with salicylic acid and hydroxyquinol as coformers. Cryst Growth Des 17, 3974-88.

34. Lukin S, Loncărić I, Tireli M, Stolar T, Blanco MV, Lazić P, Užarević K, Halasz I (2018) Experimental and theoretical study of selectivity in mechanochemical cocrystallization of nicotinamide with anthranilic and salicylic acid. Cryst Growth Des 18, 1539-47.

35. Park Y, Lee J, Lee SH, Choi HG, Mao C, Kang SK, Choi SE, Lee EH (2013) Crystal structures of tetramorphic forms of donepezil and energy/temperature phase diagram via direct heat capacity measurements. Cryst Growth Des 13, 5450-8.

36. Adin I, Iustain C, Arad O, Kaspi J (2006) Crystalline Forms of Donepezil Base, US patent, US20060122226A1.

37. Ibrahim M, Nada A, Kamal DE (2005) Density functional theory and FTIR spectroscopy study of carboxyl group. Indian J Pure Ap Phy 43, 911-7.

38. Świsłocka R, Samsonowicz M, Regulska E, Lewandowski W (2006) Molecular structure of 4-aminobenzoic acid salts with alkali metals. $J$ Mol Struct 792-793, 227-38.

39. Asiri YA, Mostafa GAE (2010) Donepezil. In: Brittain HG (ed) Profiles of Drug Substances, Excipients and Related Methodology 35, Elsevier Inc., pp 117-50.

40. 4-Aminobenzoic acid (150-13-0) ${ }^{1}$ HNMR. Available online: https://www.chemicalbook.com/ SpectrumEN_150-13-0_1HNMR.htm. [accessed on 10 January 2019] 